\title{
Review
}

\section{Mechanisms of plasmid stable maintenance with special focus on plasmid addiction systems ${ }^{\star}$}

\author{
Urszula Zielenkiewicz and Piotr Cegłowski ${ }^{\bowtie}$ \\ Institute of Biochemistry and Biophysics, Polish Academy of Sciences
}

Received: 5 November, 2001, accepted: 24 November, 2001

Key words: plasmid addiction, post-segregational killing, partition; multimer resolution

\begin{abstract}
The stable inheritance of bacterial plasmids is achieved by a number of different mechanisms. Among them are resolution of plasmid oligomers into monomers, active plasmid partitioning into dividing cells and selective killing of plasmid-free segregants. A special focus is given to the last mechanism. It involves a stable toxin and an unstable antidote. The antidotes neutralize their cognate toxins or prevent their synthesis. The different decay rates of the toxins and the antidotes underlie molecular mechanisms of toxin activation in plasmid-free cells. By eliminating of plasmid-free cells from the population of plasmid-bearing ones the toxin-antidote couples therefore act as plasmid addiction systems.
\end{abstract}

Plasmids are separate, autonomous genetic elements present in a cell independently of chromosomes. Most plasmids are small: from several to $100 \mathrm{~kb}$, but sometimes they are so large that using the size criteria their distinction from the chromosome is difficult (e.g. in Vibrio cholerae, Yamaichi et al., 1999; in Rhizobium meliloti, Honeycutt et al., 1993). Different plasmids can constitute even up to $50 \%$ of bacterial DNA (e.g. in Borrelia burgdorferi, Fraser et al., 1997; Bacillus cereus, Carlson \& Kolstø, 1994). It is commonly accepted that plasmid genes do not encode information indispensable for the functioning of the host cell. However, plasmids specify numerous features advantageous for the host in specific environments, such as resistance to harmful agents, ability to degrade rare compounds, pathogenicity, toxin production, nitrogen assimilation etc.

\footnotetext{
This work was supported by the State Committee for Scientific Research (KBN, Poland) grant No. 6 P04B 00820

${ }^{\square}$ Corresponding author: Doc. Piotr Cegłowski, Institute of Biochemistry and Biophysics, A. Pawińskiego 5a, 02-106 Warszawa, Poland; tel.: (48 22) 658 4723; fax.: (48 22) 658 3646; e-mail: piotr106@ibb.waw.pl
} 
Plasmids are very widely distributed among Prokaryota and, in general, are inherited with a high degree of stability. In special environmental conditions some plasmid genes confer a selective advantage. But, in many cases, plasmids are retained over generations without any selective pressure. Thus, there have to exist mechanisms which enable the maintenance of the plasmid during cell growth in nonselective conditions. Systems that contribute to this stability are encoded by DNA cassettes and are, in most cases, independent of one another. A particular plasmid can carry different stabilizing cassettes. Even more, cassettes from different plasmids may be combined to give a stable replicon.

\section{RANDOM- AND BETTER-THAN- RANDOM PLASMID DISTRIBUTION}

During the process of cell division plasmid copies are distributed between two descendants. If plasmid distribution within a growing cell is random, in the "ideal replicon", it is the number of plasmid molecules inside the dividing cell that determines the probability $\left(\mathrm{P}_{0}\right)$ that one of the daughters will be plasmid free (Nordström \& Austin, 1989): $\mathrm{P}_{0}=2^{(1-n)}$ , where $n$ is the number of plasmid copies. Therefore, a cell having 30 plasmid copies at the time of division would produce in $10^{9}$ cells only two plasmid-free ones, whereas in the case of 5 copies, the chance of giving a plasmid-free cell is as much as 1 per 16 .

As long as the plasmid copy number remains high, the subpopulation of plasmid-free cells is extremely limited. For low copy number plasmids obeying the random distribution law would mean that a significant fraction of daughter cells will be plasmid free. This is in contrast to the observed maintenance of plasmids in the host cells. Several mechanisms have been proposed, and shown to operate, to explain this discrepancy (see below). They can be divided into three classes: A, B and $\mathrm{C}$.
A - site-specific recombination systems ensuring that plasmid multimers arisen during replication and(or) recombination will be resolved and thus every monomer copy will be independently subjected to random distribution;

B - active partition process which precisely distributes plasmid copies to each daughter cell at division;

$\mathrm{C}$ - plasmid addiction systems, e.g. functions that kill or reduce growth of plasmidfree descendant cells.

While mechanisms described in class A lead to the optimization of random plasmid distribution, class $\mathrm{B}$ and $\mathrm{C}$ mechanisms ensure better than random plasmid inheritance.

\section{SITE-SPECIFIC RECOMBINATION SYSTEMS}

Identical copies of a given plasmid frequently form oligomers. This reduces the number of independent units during segregation. Moreover, since origins of plasmid replication are selected at random (Summers et al., 1993), the probability that plasmid monomers will be selected for replication is, for instance, two-fold lower than for plasmid dimers. Consequently, dimers will out-replicate monomers. The outcome of this 'dimer catastrophe' (Summers et al., 1993) would be a considerable plasmid loss from the host cells. To ensure a plasmid distribution process to be highly efficient, there is a need for every plasmid copy to be accessible for distribution. This is achieved by site-specific recombination systems, also called mrs - multimer resolution systems. In this process plasmid oligomers naturally formed during replication or recombination are resolved into monomers increasing the number of independent molecules accessible for distribution.

The multimer resolution systems consist of a site-specific recombinase, so called resolvase, and the defined nucleotide sequence res located on the plasmid. By specific recombina- 
tion between repeated res sequences, the recombinase resolves oligomers to monomers. The mrs systems can be encoded entirely by the plasmid (e.g. loxP-cre of P1; Austin et al., 1981) or combine the res site of the plasmid with a host encoded recombinase (e.g. cer of ColE1 and host xerC, xerD, argR, pepA; Summers \& Sherrat, 1984; Sharpe et al., 1999).

The multimer resolution systems of the inc 18 plasmid family from Gram-positive bacteria, although encoded by plasmids, require the host factor Hbsu to mediate resolution (Rojo \& Alonso, 1994; Alonso et al., 1995; Janniére et al., 1996).

In the majority of high-copy number plasmids, the multimer resolution system is the sole additional mechanism influencing their stable inheritance (for a review see Nordstrom \& Austin, 1989; Hiraga, 1992; Summers, 1998). In combination with the copy number and cell division control it ensures a very low frequency of plasmid loss.

\section{ACTIVE PARTITION}

Many plasmids, especially those having moderate or low copy number, possess an active (i.e. energy consuming) mechanism for pre- is very efficient (for example: the probability of loss of $\mathrm{P} 1$ prophage, which is present as one extrachromosomal unit in the cell, is $<1$ in $10^{5}$ per generation; Abeles et al., 1985).

Models for the active partitioning process include the pairing of plasmid molecules at cis-acting sites and subsequent separation of single plasmid copies to the opposite poles of the cell. The involvement of cellular components in the process of plasmid separation is proposed (Watanabe et al., 1989; Bignell et al., 1999).

The partition process is carried out by two proteins usually designated as A and B. The genetic organization of various partition systems is similar, with the gene for the A protein preceding the protein B-encoding gene and an adjacent centromere-like DNA sequence. As an example, the structure of the partition operon of $\mathrm{P} 1$ plasmid is shown (Fig. 1).

The partition operons are negatively autoregulated by protein A (i.e. plasmids P1, F) or protein B (i.e. plasmids NR1, R1, pTAR). The repressor activity of one protein can be enhanced by the other. The tight regulation of par operons expression is very important since an excess of protein B leads to plasmid destabilization (i.e. SopB of F plasmid; Kusukawa et al., 1987; ParB of P1; Łobocka \&

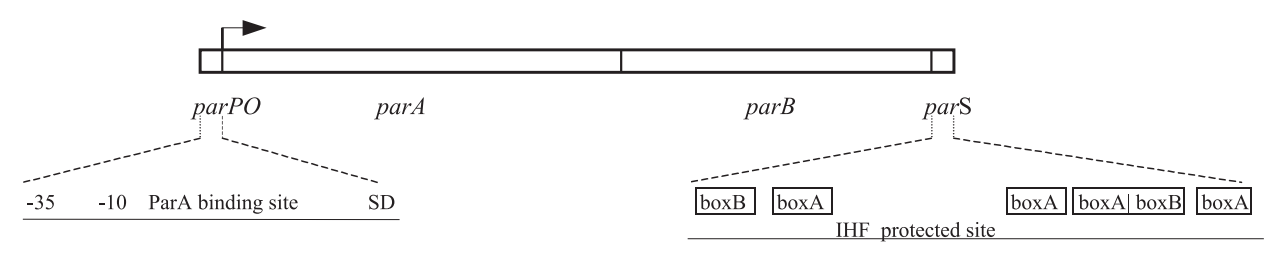

Figure 1. Schematic representation of the par operon organization of P1 plasmid.

The promoter-operator parPO and parS regions are blown up. Binding sites for ParB protein are boxed. Broken arrow indicates the promoter.

cise distribution prior to cell division of available plasmid copies to prospective daughter cells. This process, named by analogy to chromosome partitioning, as active partitioning,
Yarmolinsky, 1996). Protein B excess can also silence genes flanking the cis-acting sites (up to several kilobases away) by polymerization along the DNA starting from a certain point, 
as has been shown for SopB (Lynch \& Wang, 1995) and ParB (Rodionov et al., 1999).

All three components, partition proteins A, $\mathrm{B}$ and par site, are required for partition. The ParB proteins bind specifically to their cognate cis-acting DNA sequences termed centromere-like regions (Mori et al., 1989; Watanabe et al., 1989). These cis-acting sites are located downstream (plasmids P1, F, RK2) or upstream (NR1, R1, pTAR) from par genes. Their structure is unique for different plasmids, but always contains a characteristic number of iterated repeats which are the sites for specific binding of protein $B$.

A motif characteristic for proteins showing ATPase activity is found in partition A proteins suggesting their role in providing energy necessary for the process (Motallebi-Veshareh et al., 1990; Davies et al., 1991). On the basis of sequence similarity ParA proteins from different plasmids can be grouped into two quite distinct families: those with conserved Walker motif of ATPases and those showing homology to actin-like ATPases (Gerdes et al., 2000). Based on sequence analysis of proteins related to the ParF protein from the multidrug resistance plasmid TP228, Hayes proposed recently (Hayes, 2000) the existence of a third distinct subgroup of the ParA superfamily, evolutionarily related to the MinD subgroup of cell division proteins. Proteins of the ParB group are significantly more diverse and difficult to classify.

Recent experiments with fluorescence microscopy have visualized bona fide plasmid positioning during the time of cell growth at one- and three-quarter distance to cell poles, (plasmids F, Kim \& Wang, 1998; P1, Erdmann et al., 1999; and RK2, Bignell et al., 1999) or at the mid-cell with subsequent movement to opposite cell poles (plasmid R1, Jensen \& Gerdes, 1999), correlated with the presence of ParB proteins. The factors involved in the process of plasmid DNA movement are still unknown.

Chromosomal homologues of plasmid partition proteins have been identified in many bacteria, including Bacillus subtilis, Caulobacter crescentus and Pseudomonas putida. Their role in chromosome segregation has been shown for example in B. subtilis (locus soj-spo0J; Sharpe \& Errington, 1996; 1998) or C. crescentus (genes parA, parB and parS; Mohl \& Gober, 1997). In spite of a functional similarity between chromosome and plasmid partitioning these two processes proceed distinctly (Gordon et al., 1997).

\section{PLASMID ADDICTION SYSTEMS}

Independently of the processes that increase the probability of receiving a plasmid by a dividing cell there are very special strategies adopted by plasmids preventing plasmid-free segregants from surviving.

The idea of an "addiction" mechanism leading to very efficient plasmid maintenance comes from Koyama (Koyama et al., 1975). In his considerations he pointed out that if cells that lose an established plasmid die, the population would never contain viable cured cells. Terms like killer system, killing-antikilling, post-segregational killing, toxinantitoxin, poison-antidote, plasmid addiction system or programmed cell death are all used to describe the situation when the host cell is selectively killed if it has not received any copy of the plasmid.

The molecular basis of this killing requires the existence of at least two plasmid genes: one specifying a stable toxic agent and another coding for an unstable factor which prevents the lethal action of the toxin. While the toxin is always a protein, the antidote is either antisense RNA (which inhibits translation of toxin mRNA) or a protein (Jensen \& Gerdes, 1985).

\section{Antisense RNA regulated plasmid addiction systems}

Plasmid stabilization systems regulated by antisense RNA constitute a well conserved 
group called the hok-sok family (the name reflecting functions of the host killing and suppression of killing genes from plasmid R1) extensively studied and described in detail by Gerdes (Gerdes et al., 1997). This family has been found only in Gram-negative bacteria (see Table 1).
Sok-RNA is very labile (half-life about $30 \mathrm{sec}$ ), hok mRNA is stable for hours (Gerdes et al.,1988).

The hok mRNA exists in a plasmid-carrying cell in two forms: the inert full-length and a shorter active one. In full-length hok mRNA the "fold-back-inhibition" element ( $f b i$ ) present

Table 1. Plasmid- and chromosome-encoded hok homologues

\begin{tabular}{|c|c|c|}
\hline Locus & Replicon & References \\
\hline hok/sok & R1 & Gerdes et al., 1990 \\
\hline$f l m$ & $\mathrm{~F}$ & Loh et al., 1988 \\
\hline $\operatorname{srn} \mathrm{B}$ & $\mathrm{F}$ & Ono et al., 1986 \\
\hline pnd & $\mathrm{R} 483$ & Ono et al., 1987; Gerdes et al., 1992 \\
\hline pnd & $\mathrm{R} 16$ & Sakikawa et al., 1989; Gerdes et al., 1992 \\
\hline pnd & R64 & Furuya \& Komano, 1996 \\
\hline hokA & E. coli $\mathrm{C}$ & Pedersen et al., 1997 \\
\hline hokX & E. coli $\mathrm{B}$ & Pedersen \& Gerdes, 1999 \\
\hline hokB & E. coli $\mathrm{K} 12$ & Gerdes et al., 1997 \\
\hline hokC (gef) & E. coli ECOR24 & Poulsen et al., 1989 \\
\hline hokD (relF) & E. coli $\mathrm{K} 12$ & Bech et al., 1985; Gerdes et al., 1986 \\
\hline hokE & E. coli $\mathrm{K} 12$ & Gerdes et al., 1997 \\
\hline hokH & H. alvei & Fecker et al., 1997 Gerdes et al., 1997 \\
\hline
\end{tabular}

A model of the genetic organization of the hok-sok system is presented in Fig. 2.

The locus consists of three juxtaposed genes: hok specifying a toxin, mok (modulation of killing) required for expression and regulation of hok translation and sok coding for antisense RNA complementary to the hok mRNA leader region. Whereas

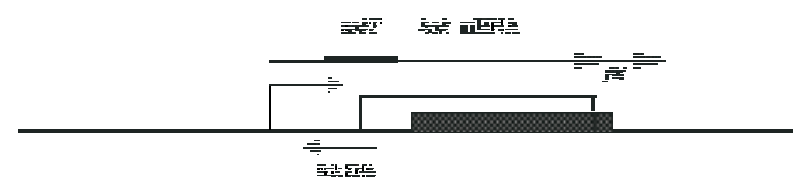

Figure 2. Schematic representation of the hok-sok system organization.

The shadowed box represents Hok toxin; open box, the mok regulatory gene; Sok-RNA, antisense RNA, and sokT, Sok-RNA target region. The thick, thin and broken arrows represent hok mRNAs, sok antisense RNA and promoter, respectively. In the full length mRNA the presence of $f b i$, the fold-back-inhibition element, is indicated. at $3^{\prime}$ end pairs with the $5^{\prime}$ end giving an RNA structure inactive both in translation and antisense RNA binding (Thisted et al., 1994a). In this form hok mRNA is accumulated inside the cell. The full-length stable form is slowly processed at the $3^{\prime}$ end (Thisted et al., 1994b). After removal of the $f b i$ element, a refolded structure of hok mRNA is accessible for antisense RNA binding and for translation. The constitutively expressed 67nt Sok-RNA binds to the leader sequence of hok mRNA. This complex is immediately cleaved by RNase III (Gerdes et al., 1992), thus impeding translation of hok mRNA. In a plasmid-free cell, the absence of Sok-RNA (degraded by RNaseE) enables the translation of hok mRNA.

Hok-like proteins are small (about 50aa), membrane-associated polypeptides. Overexpression of Hok leads to a decrease of cell membrane potential, arrest of respiration and efflux of small molecules, resulting in cell 
death (giving rise to characteristic "ghost" in phase-contrast microscopy).

The hok-sok systems may be very efficient. The stabilization of unrelated replicons ranges between 50 (for high copy number plasmid) and 10000 fold (for low copy number plasmids), as compared to random distribution (Wu \& Wood, 1994).

A number of homologues of hok-sok genes from R1 plasmid system have been identified on other plasmids (see Table 1). If tested, all of them were able to post-segregational killing in a manner similar to R1. In contrast, homologues of this family found on bacterial chromosomes are not functioning as post-segregational killing agents. However, when placed on a plasmid they clearly showed all characteristics of the hok-sok genes products including the active toxic transmembrane protein (e.g. hocC (=gef) (Poulsen et al., 1989) and hocD (=relF) (Gerdes et al., 1986). The origin and possible functions of these genes, widely distributed in bacterial chromosomes, remain mysterious.

The antisense RNA-regulated stability determinant has been also found in Gram-positive bacteria. This determinant, designated par, stabilizes the enteroccocal plasmid pAD1 (Weaver et al., 1996) and has no homology to the hok-sok family. The 400nt long par region encodes two small, convergently transcribed RNAs (210nt long RNA I and 65nt long RNA II), with 33 codons for the fst (faecalis plasmid-stabilizng toxin) peptide inside the longer RNA I. The smaller RNA II shows high degree of complementarity to RNA I. Complex formation between RNA I and the antisense RNA II was recently demonstrated in vitro (Greenfield \& Weaver, 2000). In this complex RNA II inhibits fst translation by preventing ribosome binding to the SD sequence sequestered between complementary direct repeats.

The half-life of RNA II (about $10 \mathrm{~min}$ ) is substantially shorter then that of RNA I ( $>1 \mathrm{~h}$ ) (Greenfield et al., 2000) as expected for antisense-regulated stabilizing systems. Overproduction of RNA I (or Fst peptide) causes host cell death (Weaver \& Clawell, 1989). The lethal action of Fst can be prevented by supplying RNA II in excess (Weaver et al., 1996).

\section{PROTEIC PLASMID ADDICTION SYSTEMS (PPAS)}

\section{Common features of the proteic plasmid ad- diction systems}

As mentioned above, in PPAS both the toxin and its antagonist (preventing agent) are proteins. Its functioning as the post-segregational killing system is based on different decay rates of two proteins involved: the toxin is much more stable than the antidote. This can be shown by provoking synchronous plasmid curing by inhibiting plasmid replication without affecting cell growth and division (Jensen et al., 1995).

The antidote prevents the lethal action of its cognate toxin by forming a tight complex with it. So, as long as the antidote protein remains in excess relative to the toxin, the activity of the toxin is blocked. In a cured cell, when de novo synthesis of plasmid encoded proteins is impossible, the concentration of antidote decreases quickly due to degradation by cellular proteases. The toxin, now released from the complex, executes its toxicity causing the cell death. Thus, in a population only cells carrying the plasmid will exist (Fig. 3).

All PPAS have similar genetic organization, shown schematically in Fig. 4.

In all described cases the genes constituting proteic killer systems are organized in operons. With one exception of pRts1 (Tian et $a l ., 1996)$, the first cistron encodes the antidote and the second the toxin.

An important characteristic of these operons is their autoregulation at the transcriptional level. The antidote protein itself or in a complex with the toxin is a repressor of the promoter in question. In the majority of cases, toxins enhance the promoter repression by the antidote (e.g.: plasmid P1, 


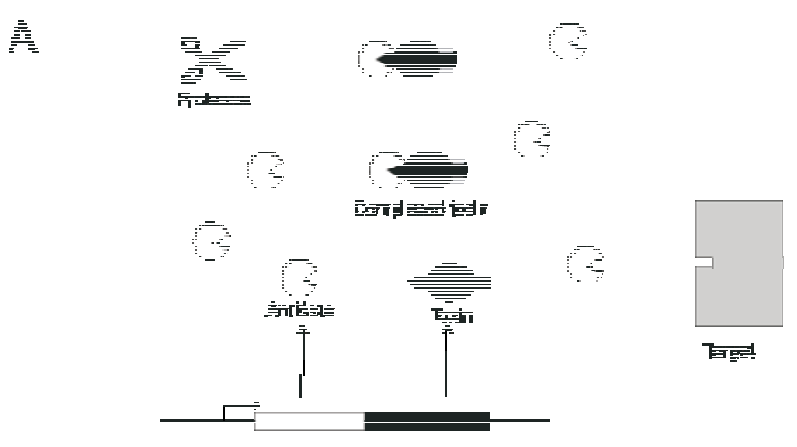

豆
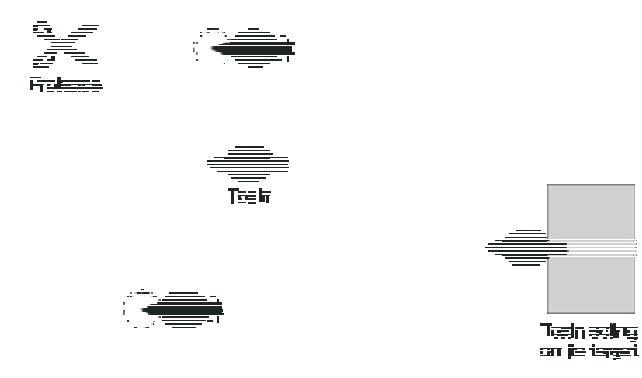

Figure 3. The principle of PPAS functioning.

A. In a plasmid-bearing cell: both proteins, the antidote and the toxin, are produced. The antidote (constantly present in excess) neutralizes the toxin by complex formation. B. In cell after plasmid loss: the synthesis of both, the antidote and toxin proteins does not occur. The antidote becomes degraded by cellular protease(s) and the toxin remains free. The uncomplexed toxin acts against its cellular target.

Magnuson \& Yarmolinsky, 1998; R1, RuizEchevarria et al., 1991b; pTF-FC2; Smith \& Rawlings, 1998). In case of F1 plasmid, a complex of both the CcdA and CcdB proteins is needed for the autoregulation of the ccd operon (Tam \& Kline, 1989). In contrast, the autoregulation of the PPAS encoded by pSM19035 plasmid does not include neither the antidote nor the toxin; it is achieved by a third component that exclusively plays a role of the transcriptional repressor (de la $\mathrm{Hoz}$ et $a l ., 2000)$. Precise autoregulation seems to be a prerequisite for proper functioning of the stabilizing systems.

The antidote proteins are present in excess to the toxins in bacterial cells. Their half-life times in vivo are significantly shorter than those of the toxins due to degradation by cellular proteases, as indicated in Table 2.
Proteins of PPAS are generally rather small (about 70aa-130aa), the toxin usually being slightly bigger than the corresponding antitoxin. The only exceptions are the hig locus of Rts1 plasmid with a 104aa antidote versus a 90aa toxin and a large toxin Zeta protein (287aa) in the $\omega-\varepsilon-\zeta$ system of pSM19035 (see Fig. 4). All PPAS toxins act from within the host cell.

In spite of the structural and functional similarity of various PPAS systems there is no significant sequence identity among their genes. The only weak amino-acid sequence similarity was detected between CcdA of F plasmid and Kis of R1 (Ruiz-Echevarría et al., 1991a) as well as between ParD of RK2 and PasA of pTF-FC2 (Smith \& Rawlings, 1997). Instead, it is very common to find highly conserved sequences responsible for plasmid stability on many related plasmids which probably illustrates horizontal transfer of genes between different plasmids and bacteria (Gerdes, 2000; Hayes, 1998).

There is no uniform pattern for the placement of stability cassettes on plasmids, although in a few cases a position close to the origin of replication (e.g. $c c d$ of $\mathrm{F}$ plasmid and phd/doc of P1 plasmid) could be pointed out.

Names given to particular stabilizing loci are not consistent. In the majority of cases they try to describe the observed behaviour of cells when stabilizing genes are activated. As, historically, the function of this type of genes was difficult to distinguish from partitioning, quite often the misleading name par is used for stability genes. The $\boldsymbol{s t} \boldsymbol{b}$ abbreviation of $s t a-$ bility becomes frequent in recent literature.

\section{EXAMPLES OF THE BETTER CHARACTERIZED PROTEIC PLASMID ADDICTION SYSTEMS}

\section{ccd locus of plasmid $\mathrm{F}$}

The ccd locus of plasmid $\mathrm{F}$ is the best characterized post-segregational proteic killer system. The large, $95 \mathrm{~kb}$ conjugative plasmid $\mathrm{F}$ 


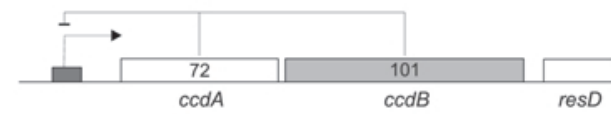

ccd of $\mathrm{F}$
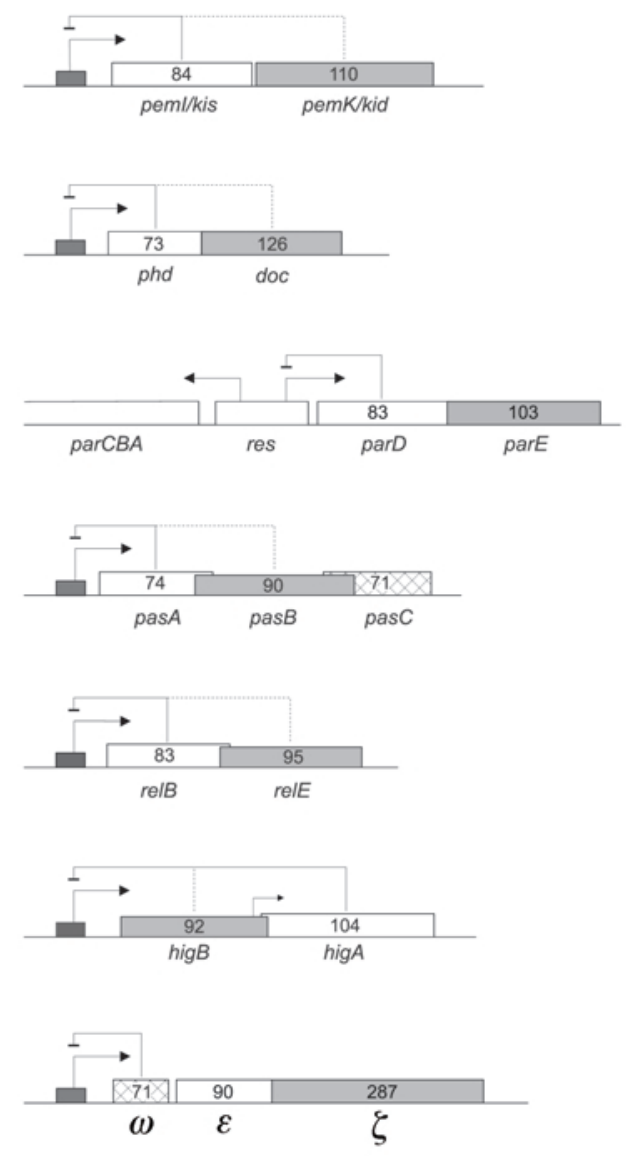

Figure 4. Genetic organization of PPAS operons.

Bars represent: open - antidotes, grey - toxins and hatched - additional elements, respectively. Arrows indicate promoters. Autoregulatory circuits are shown for every system. Continuos and discontinuos lines indicate genes directly involved in autoregulation and enhancement of autoregulatory activity, respectively. See text for details.

exists in $E$. coli cells in only one or two copies per chromosome. Yet it is extremely well maintained in a growing population. This high degree of stability plasmid $\mathrm{F}$ achieves by combining the effects of multiple control elements: two functional replication systems, several site-specific recombinases, the active partition region sop and three post-segregational killing systems (Nordström \& Austin, 1989). The flm (F leading maintenance) locus and srnB (stable RNA degradation) locus are homologous to the hok/sok family regulated by antisense RNA (Golub \& Panzer, 1988; Ohnishi et al., 1977; Nielsen et al., 1991).
The name of the ccd locus (coupled cell division) originates from the observation (Ogura \& Hiraga, 1983; Miki et al., 1984) that cell division is dependent on previous replication of $\mathrm{F}$ plasmid. This inadequate description was later deciphered using the same letters as control of cell death (Van Melderen et al., 1994). Indeed, it was shown (Jaffé et al., 1985) that genes of the $c c d$ locus mediate plasmid maintenance primarily by killing plasmid-free segregants.

The $c c d$ locus is composed of two genes: ccdA and $\boldsymbol{c c d} \boldsymbol{B}$ (also called $\boldsymbol{H}$ and $\boldsymbol{G}$ or $\operatorname{let} \boldsymbol{A}$ and $\boldsymbol{l e t} B$, respectively) encoding the correspond- 
Table 2. Examples of proteic plasmid addiction systems

\begin{tabular}{clccccc}
\hline System & Plasmid & Toxin & Antidote & $\begin{array}{c}\text { Protease } \\
\text { degrading } \\
\text { antidote }\end{array}$ & Target & Reference \\
\hline ccd & F & CcdB & CcdA & Lon & gyrase & Jaffé et al., 1985 \\
pem/parD & R100/R1 & PemK/Kid & PemI/Kis & Lon & DnaB & Tsuchimoto et al., 1988 \\
phd-doc & P1 & Doc & Phd & ClpXP & unknown & $\begin{array}{c}\text { Bravo } \text { et al., 1987 } \\
\text { Lehnherr } \text { et al., 1993 }\end{array}$ \\
parDE & RK2/RP4 & ParE & ParD & unknown & unknown & Roberts et al., 1990 \\
pas & TF-FC2 & PasB & PasA & Lon & unknown & Smith \& Rawlings, 1997 \\
relBE/stbDE & P307/R485 & RelE/StbE & RelB/StbD & Lon & unknown & Grønlund \& Gerdes, 1999 \\
hig & Rts1 & HigB & HigA & unknown & unknown & $\begin{array}{c}\text { Hayes, 1998 } \\
\text { Tian } \text { et al., 1996 }\end{array}$ \\
\hline
\end{tabular}

ing proteins: the $\mathrm{Ccd} \mathrm{A}$ antidote and the $\mathrm{CcdB}$ toxin (Bex et al., 1983; Miki et al., 1984). These genes are organized in an operon together with the resolvase-encoding gene resD (Lane et al., 1986). Expression of the operon is negatively controlled by a complex of the two Ccd proteins (de Feyter et al., 1989). The domains of both proteins involved in autoregulation are different from those responsible for the killing-antikilling effect (Salmon et al., 1994; Bahassi et al., 1995). In the absence of the CcdA antidote, $\mathrm{CcdB}$ causes a reduction in DNA synthesis (Jaffé et al., 1985), activation of the SOS regulon (Karoui et al., 1983; Reece \& Maxwell, 1991), cell filamentation (Miki et $a l ., 1984$ ), formation of anucleate cells and, as a consequence, cell death (Jaffé et al., 1985).

Bacterial mutants resistant (Bernard \& Couturier, 1992) and tolerant (Miki et al., 1992 ) to the lethal activity of $\mathrm{CcdB}$ were altered in the gyrA gene. The product of gyrA constitutes a part of an essential enzym - gyrase, responsible for introducing negative supercoils in DNA. During the breaking and rejoining reaction, the 5 '-ends of substrate DNA are covalently linked to the A subunit of gyrase. The CcdB toxin traps the cleaved DNA-gyrase complex and impedes the resealing of the nicked DNA (Bernard \& Couturier, 1992; Bernard et al., 1993). Formation of double-strand breaks in the DNA, in turn, induces the SOS response.

In addition, the $\mathrm{CcdB}$ protein is a direct inhibitor of gyrase (Miki et al., 1992). In the absence of covalently bound DNA CcdB binds to free GyrA subunit making gyrase catalytically inactive. Both $\mathrm{CcdB}$ activities are suppressed by the same mutations in GyrA (substitution R462C leading to resistance to CcdB; Bernard et al., 1993) and in CcdB (mutations in the three carboxy-terminal amino acids that annul the lethal activity of CcdB; Bahassi et al., 1995).

The recently determined crystal structures of a large, $59 \mathrm{kDa}$, fragment of the amino-terminal region of GyrA (Berger et al., 1996) have led to a model for the GyrA-CcdB complex formation (Lorris et al., 1999). The model accommodates the critical C-terminus of the toxin dimer in the central hole of a GyrA dimer during its cycling on DNA, impeding the closing stage and therefore the religation of nicked DNA. The CcdA antidote not only prevents this complex formation, but also releases CcdB from inactive complexes by forming a new tight CcdA-CcdB complex (Bernard et al., 1993; Maki et al., 1996).

The ATP-dependent serine protease Lon is responsible for degradation of CcdA. The half-life of the CcdA protein was estimated to 
be about $1 \mathrm{~h}$, whilst CcdB remained stable for over 2 h (Van Melderen et al., 1994).

Among the F plasmid encoded stability cassettes, the $c c d$ system is a rather inefficient one: only 10-fold stabilisation is achieved, compared to 100 -fold for flm or 1000-fold for sop (Jensen et al., 1995; Boe et al., 1987). Perhaps, as the CcdB toxin primarily induces the SOS regulon, rather than immediate cell death, part of its role may be to generate genetic diversity in those bacteria which do not have the $\mathrm{F}$ plasmid after division (Couturier et al., 1998).

\section{pem/parD locus of plasmids R100/R1}

This is the second (and so far the last) PPAS with a known cellular target of lethal action. Loci described as pem (plasmid emergency maintenance) for plasmid R100 (Tsuchimoto et al., 1988) and as parD for plasmid R1 (Bravo et al., 1987) encode the antitoxin PemI identical to Kis (killing suppressor) and toxin PemK identical to Kid (killing determinant).

The pem/parD operon possesses the canonical features of PPAS: it encodes two small proteins with the gene for the antitoxin preceding that for the toxin; it is autoregulated at the level of transcription by a complex of the two proteins involved and the decay time for these proteins is different. The degradation of the antidote PemI/Kis is due to the Lon protease (Tsuchimoto et al., 1992).

In vitro, it has been shown that the Kis and Kid proteins form a complex. Also, DnaB-dependent initiation of plasmid ColE1 replication was specifically inhibited by the addition of Kid. The replication was restored when the antidote Kis was added. In vivo, inhibition of lytic $\lambda$ prophage induction (whose replication initiation is DnaB dependent) was observed after inactivation of the antagonist protein Kis. Furthermore, overproduction of DnaB suppressed the lethal action of Kid in vivo (Ruiz-Echevarría et al., 1995). Taking this into account, it seems well documented that the cellular target of the action of the
PemK/Kid protein is DnaB helicase. The primary effect of the pem/parD system in a majority of strains is cell division inhibition rather than killing of the plasmid-free segregants (Tsuchimoto \& Ohtsubo, 1989; Jensen et al., 1995) thus explaining its modest, less than 10-fold, plasmid stabilization.

\section{phd-doc locus of bacteriophage P1}

Bacteriophage P1 lysogenizes E. coli cells as an extremaly low-copy number plasmid. Its stable maintenance within bacterial cells is ensured, in part, by an addiction mechanism mediated by two specific proteins: the antidote Phd (prevent host death) and the toxin Doc (death on cure), (Lehnherr et al., 1993). The corresponding genes phd and doc are organized in an operon, the transcription of which is negatively autoregulated by $\mathrm{Phd}$ (two dimers of the Phd protein bind to the operator, Gazit \& Sauer, 1999) and enhanced by the Doc protein (Magnuson \& Yarmolinsky, 1998).

Free Phd protein (unbound to the operator or Doc) exists predominantly in an unfolded conformation and is subject to degradation by the ATP-dependent serine protease ClpXP (Lehnherr \& Yarmolinsky, 1995). Physical binding between the prophage stabilizing proteins was shown for a nontoxic mutant of Doc in vitro (Gazit \& Sauer, 1999). The cellular target of the action of Doc remains unknown but under conditions of its action the protein synthesis is inhibited. Recently it was demonstrated that post-segregational killing induced by $p h d-d o c$ addiction genes requires mazEF chromosomal system (Hazan et al., 2001). The phd-doc system stabilizes mini P1 plasmid about 7-fold (Lehnherr et al., 1993).

\section{parDE locus of plasmids RK2/RP4}

The broad-host-range plasmid RK2 $(60 \mathrm{~kb}$, identical to the plasmid RP4, IncP incompatibility group) is maintained at the relatively low number of 5-8 copies per chromosome 
and is very stable in a wide range of Gram-negative bacteria.

The investigation of separate loci involved in the stable maintenance of plasmids from the IncP incompatibility group is extremely difficult because of the interrelated co-ordinated regulation of the vital functions by the plasmid central control region ccr. The juxtaposited influence of the regulatory proteins KorA and KorB on transcription of many promoters makes the final effect of the propagation of IncP plasmids particularly dependent on the host strain and conditions of cultivation.

The parDE operon responsible for post-segregational killing of plasmid-free cells is located inside the par locus together with the par $\boldsymbol{C B A}$ operon encoding a site-specific recombination system (Grinter et al., 1989; Roberts et al., 1990; Roberts \& Helinski, 1994).

Expression of the ParE protein in the absence of ParD leads to growth inhibition and filamentation of the cells. An uncharacterized region $p s a$ has been postulated to be responsible for growth arrest not involving filamentation (Jovanovic et al., 1994). The cellular target of the toxin is not known. The effect of the functioning of the parDE operon on bacterial growth and morphology is dependent on the host strain and the type of medium in a manner which is not well understood (Roberts et al., 1994).

Both proteins, ParD and ParE, exist as dimers in solution and form tetrameric complexes in vitro (Johnson et al., 1996). The antidote ParD negatively regulates transcription of the parDE operon (Roberts et al., 1993).

In its natural context, the expression of the parDE operon might be subject to global regulation by the KorA and KorB proteins (Pansegrau et al., 1994). Perhaps this is the reason that, unexpected for proteic killer system, when tested in a control system (Jensen et al., 1995) containing the parDE operon only, this cassette exerts a 100 -fold stabilizing effectiveness. The sole effect of stabilization in the case of conjugal plasmids may be additionally masked by the simultaneous transfer of the plasmid to the plasmid-free cells (Easter et al., 1997).

The RK2 plasmid also carries several potentially host-lethal $\boldsymbol{k i l}$ loci (kilA, B, C and $\boldsymbol{E}$ also denominated as $\boldsymbol{k l a}, \boldsymbol{k l b}, \boldsymbol{k l c}$ and $\boldsymbol{k l e}$ ). kilB is involved in conjugal transfer (MotallebiVeshareh et al., 1992). The function of other kil genes is unknown, but their unregulated expression can lead to the death of host $E$. coli cells (Figurski et al., 1982).

An intriguing question whether the parDE operon works in concert with the second par operon parCBA comes from the comparison with the resolution of dimer chromosomes coupled to cell division (Steiner \& Kuempel, 1998).

\section{pas locus of plasmid pTF-FC2}

An unusual proteic plasmid addiction system has been described for the broad host range plasmid pTF-FC2 from the biomining bacterium Thiobacillus ferrooxidans.

The pas (plasmid addiction system) locus consists of three genes: pasA, B and C. PasA encodes an antitoxin, pas $B$ a toxin, and pas $C$ a protein which enhances the ability of the PasA antidote to neutralise the toxic effect of PasB. Nevertheless, the pair PasA and PasB is equally efficient in plasmid stabilization in the presence or absence of PasC (Smith \& Rawlings, 1997).

The proteins PasA and PasB, but not PasC, are required for the full repression of the pas operon (Smith \& Rawlings, 1998b). Precise autoregulation of the pas operon is very important for its functioning - placing the pas genes under a heterologous promoter results in a complete loss of the test plasmid stability (Smith \& Rawlings, 1998b).

The efficiency of the pTF-FC2 pas poison-antidote stability system in E. coli is greatly affected by the host strain: from 100-fold in CSH50 to no increase in JM109. The Lon protease is responsible for degrada- 
tion of the antidote PasA (Smith \& Rawlings, 1998a).

Although the specific action of the PasB toxin is still unknown and the stabilization efficiency is modest, the pas $A B C$ system undoubtedly falls into the bactericidal category as shown in in vivo experiments (Smith \& Rawlings, 1997).

The pTF-FC2 PasA antitoxin is poorly but clearly related ( $31 \%$ aa identity) to the ParD antitoxin of the parDE system of RK2 plasmid.

\section{relBE/stbDE locus of plasmids P307/R485}

Recently discovered on enteropathogenic plasmid P307 from E. coli, the stability system relBE shares about $50 \%$ sequence identity with $\boldsymbol{s t b} \boldsymbol{D E}$ genes on R485 plasmid from Morganella morganii (Grønlund \& Gerdes, 1999; Hayes, 1998).

Its structural organization is canonical for the toxin-antitoxin genes family with the autoregulatory relB gene encoding an antidote and the overlapping $\mathbf{r e l E}$ gene encoding a toxin. When overproduced, the relE gene causes immediate decline in viable counts over 5 orders of magnitude, indicating that RelE is a very potent toxin. The killing by RelE can be counteracted by the induction of RelB expression. The protease responsible for RelB degradation is Lon. The relBE operon is able to stabilize a mini-P307 replicon.

Homologues of the relBE/stbDE operon have been found on Gram-negative bacterial chromosomes. The relBEF operon of $E$. coli chromosome was found to be affected in stringent control during amino-acid starvation (so called "delayed relaxed response", Lavallé, 1965). RelB mutants had an increased level of relBEF $\mathrm{mRNA}$ and the growth recovered very slowly after the termination of amino acid starvation (Bech et al., 1985). In this context the proposed action for the RelE toxin is inhibition of translation (Gotfredsen \& Gerdes, 1998).
The locus relBE, at the moment of discovery assigned only to pathogenic bacteria, now seems unexpectedly widely distributed among prokaryotic chromosomes.

\section{hig locus of plasmid Rts1}

Compared with other proteic killer genes, the hig (host inhibition of growth) locus of plasmid Rts1 is unique in that the toxic part $\boldsymbol{h i g} \boldsymbol{B}$ lies upstream of the antidote gene $\boldsymbol{h i g} \boldsymbol{A}$.

The protein products of the two overlapping genes have been identified: the 92aa killer factor of $h i g B$ and the 104aa antitoxin of higA. HigA suppresses the HigB function both in cis and in trans. Two promoters were shown to be active in the hig operon: a stronger one upstream of $h i g B$, negatively regulated by the HigA antidote, and a weaker but constitutive one upstream of $h i g A$, within the higB coding region (Tian et al., 1996b).

The cellular target of the action of HigB remains unknown.

\section{$\omega-\varepsilon-\zeta$ locus of plasmid pSM19035}

The $\omega-\varepsilon-\zeta$ operon of the low-copy-number, broad-host-range plasmid pSM19035 from Streptococcus pyogenes encodes the only proteic addiction system discovered in Gram positive bacteria. It consists of three genes: $\omega$, $\varepsilon$ and $\zeta$. Two of them, $\varepsilon$ and $\xi$, encode PPAS with Zeta (the product of $\zeta$ ) acting as a toxin and Epsilon (the product of $\varepsilon$ ) as an antidote. This system is unique in that neither the antidote nor the antidote-toxin complex are involved in regulation of their own synthesis. The autoregulatory functions are exclusively played here by a third component of the operon, $\omega$ gene. It has been shown that $\omega$ is also implicated in regulation of expression of two other pSM19035 genes: $\delta$ and $\operatorname{cop} S$. Delta belongs to a family of ATPases involved in active partitioning and CopS regulates plasmid copy number. Hence, Omega-repressor links random (plasmid-copy-number control) and 
better-than-random (PPAS, putative partitioning) inheritance of pSM19035 (de la Hoz et al., 2000).

The $\omega-\varepsilon-\xi$ operon was shown to stabilize heterologous plasmids in Gram-positive bacterium B. subtilis and less efficiently in Gramnegative $E$. coli. In both organisms the toxic effects of the excess of protein Zeta were counteracted by the proper expression of the gene $\varepsilon$. In B. subtilis the activity of protein Zeta was bactericidal whereas in $E$. coli it was mainly bacteriostatic (Zielenkiewicz et al., 2000). The interaction between Epsilon and Zeta proteins was detected in vivo in yeast two-hybrid system (Gerdes et al., 2000). It is important to note the broad spectrum of the toxicity of protein Zeta: it acts against Gram-positive and Gram-negative bacteria as well as eukaryotic S. cerevisiae (Zielenkiewicz, unpublished).

The cellular target of the toxin Zeta remains unknown.

\section{CHROMOSOMALLY LOCATED TOXIN-ANTITOXIN GENES}

Many of the addiction genes found in plasmids have homologues on bacterial chromosomes. Systematic inspection of data-bases reveals that they are present in every systematic group of Prokaryota, including Archaea. Moreover, several paralogues of toxin-antitoxin genes are frequently repeated on the same chromosome (Gerdes, 2000).

When cloned into plasmids, these genes are able to stabilize an unstable replicon by post-segregational killing. For example, one of the two E. coli homologues of the pem locus, called $\boldsymbol{c h p A}$ (or $\boldsymbol{m a z E F}$ ) located in the rel operon was tested in detail for its killer properties (Aizenman et al., 1996). After cloning on a plasmid it was clearly demonstrated that these genes possess all of the properties required for an addiction module. MazE is a labile protein degraded by the ClpAP protease and protects the bacterial cell from the toxic effect of the stable MazF protein. Both pro- teins interact directly. Expression of $m a z E F$ is regulated by the cellular level of ppGpp, product of the activity of the protein encoded by relA gene. As shown in recent papers (Sat et al., 2001; Hazan et al., 2001) inhibition of transcription and/or translation caused by stress conditions (starvation, action of some antibiotics) or the activity of another PPAS, phd-doc, triggers mazEF lethality by preventing de novo synthesis of the short-lived antitoxin.

Irrespective of only partial amino-acid sequence identity, the ChpAI (MazE) or ChpBI (the second homologue of PemI) antitoxin can functionally interact with the PemK/Kid toxin (Santos-Sierra et al., 1997).

Recently, a new widely distributed family of genes, homologous to $E$. coli relBE has been classified as toxin-antitoxin modules (Gotfredsen \& Gerdes, 1998). Again, by use of a plasmid model, it was shown that relB specifies an antitoxin that prevents the lethal action of relE-encoded toxin; the protein RelB autoregulates the relBEF operon at the level of transcription and the genes relBE stabilize a mini-R1 test plasmid. The third gene of this operon, relF, potentially codes for a toxin belonging to the Hok family (Gerdes et al., 1986), although the cistron is not translated. Additionally, the relBE genes are clearly homologous to many operons located on different plasmids, some of them with a well documented function of an addiction system (e.g. P307; Grønlund \& Gerdes, 1999, R485; Hayes, 1998, pTF-FC2; Smith \& Rawlings, 1997).

\section{BACTERIOCINS AND OTHER OUT ACTING AGENTS ENCODED BY PLASMID}

Antagonistic interactions between related microorganisms have been noticed since the very beginning of bacteriological studies. In time, substances produced by bacteria that inhibit the growth of other vicinal bacteria from 
closely related species received the name bacteriocin.

Production of many bacteriocins is encoded on plasmids together with correspondent gene(s) specifying the immunity to them. The toxic protein is secreted outside the cell, adsorbs to specific outer membrane receptors of the sensitive cell and, consequently, inhibits or kills this cell. The bacteriocin producing cells are resistant to their own toxin thanks to the immunity gene present on a plasmid and expressed at the same time with the gene for the toxin. The detailed information on the function of bacteriocins can be found in recent reviews (Jack et al., 1995; Jack \& Jung, 2000).

The mechanism of stabilization achieved by bacteriocin killing is only superficially similar to post-segregational stabilization by addiction systems. Whereas plasmid addiction systems do not permit the progeny without a plasmid to arise, plasmids producing toxins acting from outside protect plasmid-bearing cells from competition by eliminating incoming plasmid-free cells.

To some extent, this is similar to many other phenomena like antibiotic production, pathogenicity, yeast killer viruses and the Kluyveromyces killer plasmids.

\section{RESTRICTION-MODIFICATION SYSTEMS (R-M) AS STABILITY DETERMINANTS}

A restriction endonuclease ( $R$ ) recognizes a specific short sequence on duplex DNA and makes double-strand break within or close to it, unless the modification enzyme (M) methylates this sequence protecting it from the cleavage. $\mathrm{R}-\mathrm{M}$ gene complexes are abundant in Prokaryota, including Archaea, present equally on chromosomes and plasmids. One bacterial cell can contain multiple $\mathrm{R}-\mathrm{M}$ gene pairs.

$\mathrm{R}-\mathrm{M}$ systems are believed to have evolved to protect cells from foreign DNA like viruses or plasmids. The incoming DNA is not modified at specific sequences and will be cleaved by the restriction enzyme present in the cell. But, this "cellular defense" hypothesis can hardly explain the exceptional diversity and specificity of recognition sequences. For some "rare cutter" restriction enzymes it is difficult to find foreign DNA containing such sequences.

It is also true that the $\mathrm{R}-\mathrm{M}$ pairs are not easily lost from their host cell. Those of the descendant cells that lose an RM gene cluster are unable to modify a sufficient number of recognition sequences in their chromosome to protect them from the lethal attack by the remaining restriction enzyme.

When present or moved on a plasmid, R-M gene pairs can increase apparent plasmid stability in a post-segregational host killing manner. Naito et al. (1995) have demonstrated that plasmids carrying EcoRI or PaeR7 R-M gene pairs $\left(\mathrm{r}^{+} \mathrm{m}^{+}\right)$are considerably more stable than the vector alone or plasmids with the modification gene only $\left(\mathrm{r}^{-} \mathrm{m}^{+}\right)$. When the replication of $\mathrm{r}^{+} \mathrm{m}^{+}$plasmids was temperature arrested, the number of viable cells ceased to increase as well as the number of plasmid carrying cells. The proposed explanation for the cell death after $\mathrm{r}^{+} \mathrm{m}^{+}$plasmids loss is the cleavage of the insufficiently methylated host chromosome. It was confirmed by direct observation of chromosomal DNA degradation in cured cells.

It has been experimentally demonstrated that two R-M systems of the same sequence specificity cannot simultaneously force their maintenance on a host (Kusano et al., 1995). That could be the basis of the quick evolutionary diversification of the $\mathrm{R}-\mathrm{M}$ genes.

From this perspective the restriction enzyme and its cognate methylase are like a toxin-antidote pair. The only difference is that the restriction enzyme is not interacting with the methylase directly. However, as the methylase is protecting the cellular target from the restriction enzyme attack, the latest effect of the R-M pair presence is apparent stabilization of plasmid carrying them.

All these observations allow the $\mathrm{R}-\mathrm{M}$ genes to be seen as selfish elements, evolved and 
fixed as programmed cell death modules, formally similar to plasmid addiction systems (Yarmolinsky, 1995; Kobayashi, 1998).

\section{PPAS EVOLUTION}

The origin of potentially lethal genes remains open to speculations. As the addiction cassettes are so frequent in prokaryotic chromosomes and plasmids, the hypothesis of the concentration of multiple and independent smaller replicons to give a new bigger plasmid or even a bacterial chromosome has been proposed. This is supported by an observation that the presence of multiple stability determinants on a given plasmid is often paralleled by multiple replicons (e.g. plasmids F and RK2).

Another hypothesis is proposed basing on sequence comparison among dispersed homologues (Grønlund \& Gerdes, 1999) assumed that ubiquity of relBE genes is likely due to vertical transmission of an ancestor that have appeared early in evolution before the branching of Bacteria and Archaea.

Toxin-antitoxin cassettes present on chromosomes could have become the source of genes for plasmid addiction systems (Rawlings, 1999). Once captured on a plasmid these genes would be infinitely maintained in population owing the ability to kill plasmidfree cells. At the same time the diversification and horizontal transfer of the toxin-antitoxin genes could have occurred. The opposite direction of moving genes (i.e. from plasmid to the chromosome) cannot be yet ruled out.

The abundance of killing genes on prokaryotic chromosomes also suggests their different that stabilizing functions. Since some of these genes (e.g. relBE and $\operatorname{chp} A$ ) are linked to the stringent control and their activation reduces the rate of translation (RelE) or replication (ChpA), it is now proposed that the toxin-antitoxin loci constitute a part of the global stress response (Gerdes, 2000).

The question whether toxin-antitoxin loci, plasmidic or chromosomal, are a kind of DNA self parasites, suicide cassettes for programmed bacterial cell death, elements of stress response or even beneficial in genetic diversification is still to judge.

\section{R E F E R E N C E S}

Abeles, A.L., Friedman, S.A. \& Austin, S.J. (1985) Partition of unit-copy miniplasmids to daughter cells. III. The DNA sequence and functional organization of the $\mathrm{P} 1$ partition region. J. Mol. Biol. 185, 261-272.

Aizenman, E., Engelberg-Kulka, H. \& Glaser, G. (1996) An Escherichia coli chromosomal "addiction module" regulated by guanosine $3^{\prime}, 5^{\prime}$-bispyrophosphate: A model for programmed bacterial cell death. Proc. Natl. Acad. Sci. U.S.A 93, 6059-6063.

Alonso, J.C., Weise, F. \& Rojo, F. (1995) The Bacillus subtilis histone-like protein $\mathrm{Hbsu}$ is required for DNA resolution and DNA inversion mediated by the beta recombinase of plasmid pSM19035. J. Biol. Chem. 270, 2938-2945.

Austin, S., Ziese, M. \& Sternberg, N. (1981) A novel role for site-specific recombination in maintenance of bacterial replicons. Cell 25, 729-736.

Bahassi, E.M., Salmon, M.A., Van Melderen, L., Bernard, P. \& Couturier, M. (1995) F plasmid CcdB killer protein: ccdB gene mutants coding for non-cytotoxic proteins which retain their regulatory functions. Mol. Microbiol. 15, 1031-1037.

Bahassi, E.M., O’Dea, M.H., Allali, N., Messens, J., Gellert, M. \& Couturier, M. (1999) Interactions of CcdB with DNA gyrase. Inactivation of GyrA, poisoning of the gyrase-DNA complex, and the antidote action of CcdA. J. Biol. Chem. 274, 10936-10944.

Bech, F.W., Jorgensen, S.T., Diderichsen, B. \& Karlstrom, O.H. (1985) Sequence of the relB transcription unit from Escherichia coli and identification of the relB gene. EMBO J. 4, 1059-1066.

Berger, J.M., Gamblin, S.J., Harrison, S.C. \& Wang, J.C. (1996) Structure and mechanism 
of DNA topoisomerase II. Nature $\mathbf{3 7 9}$, $225-232$.

Bernard, P. \& Couturier, M. (1992) Cell killing by the $\mathrm{F}$ plasmid $\mathrm{CcdB}$ protein involves poisoning of DNA- topoisomerase II complexes. J. Mol. Biol. 226, 735-745.

Bernard, P., Kezdy, K.E., Van Melderen, L., Steyaert, J., Wyns, L., Pato, M.L., Higgins, P.N. \& Couturier, M. (1993) The F plasmid CcdB protein induces efficient ATP-dependent DNA cleavage by gyrase. J. Mol. Biol. 234, 534-541.

Bex, F., Karoui, H., Rokeach, L., Dreze, P., Garcia, L. \& Couturier, M. (1983) Mini-F encoded proteins: identification of a new 10.5 kilodalton species. EMBO J. 2, 1853-1861.

Bignell, C.R., Haines, A.S., Khare, D. \& Thomas, C.M. (1999) Effect of growth rate and incC mutation on symmetric plasmid distribution by the IncP-1 partitioning apparatus. Mol. Microbiol. 34, 205-216.

Boe, L., Gerdes, K. \& Molin, S. (1987) Effects of genes exerting growth inhibition and plasmid stability on plasmid maintenance. J. Bacteriol. 169, 4646-4650.

Bravo, A., de Torrontegui, G. \& Diaz, R. (1987) Identification of components of a new stability system of plasmid R1, ParD, that is close to the origin of replication of this plasmid. Mol. Gen. Genet. 210, 101-110.

Carlson, C.R. \& Kolsto, A.B. (1994) A small (2.4 $\mathrm{Mb}$ ) Bacillus cereus chromosome corresponds to a conserved region of a larger (5.3 Mb) $B a$ cillus cereus chromosome. Mol. Microbiol. 13, $161-169$.

Couturier, M., Bahassi, E. \& Van Melderen, L. (1998) Bacterial death by DNA gyrase poisoning. Trends Microbiol. 6, 269-275.

Davis, M. A., Martin, K.A. \& Austin, S.J. (1992) Biochemical activities of the parA partition protein of the P1 plasmid. Mol. Microbiol. 6, 1141-1147.

Davis, M.A., Radnedge, L., Martin, K.A., Hayes, F., Youngren, B. \& Austin, S.J. (1996) The P1 ParA protein and its ATPase activity play a direct role in the segregation of plasmid copies to daughter cells. Mol. Microbiol. 21, 1029-1036.

de Feyter, R., Wallace, C. \& Lane, D. (1989) Autoregulation of the ccd operon in the $\mathrm{F}$ plasmid. Mol. Gen. Genet. 218, 481-486.

de la Hoz, A.B., Ayora, S., Sitkiewicz, I., Fernandez, S., Pankiewicz, R., Alonso, J.C. \& Cegłowski, P. (2000) Plasmid copy-number control and better-than-random segregation genes of pSM19035 share a common regulator. Proc. Natl. Acad. Sci. U.S.A 97, 728-733.

Easter, C.L., Sobecky, P.A. \& Helinski, D.R. (1997) Contribution of different segments of the par region to stable maintenance of the broadhost-range plasmid RK2. J. Bacteriol. 179, 6472-6479.

Erdmann, N., Petroff, T. \& Funnell, B.E. (1999) Intracellular localization of P1 ParB protein depends on ParA and parS. Proc. Natl. Acad. Sci. U.S.A 96, 14905-14910.

Figurski, D.H., Pohlman, R.F., Bechhofer, D.H., Prince, A.S. \& Kelton, C.A. (1982) Broad host range plasmid RK2 encodes multiple kil genes potentially lethal to Escherichia coli host cells. Proc. Natl. Acad. Sci. U.S.A 79, 1935-1939.

Fraser, C.M., Casjens, S., Huang, W.M., Sutton, G.G., Clayton, R., Lathigra, R., White, O., Ketchum, K.A., Dodson, R., Hickey, E.K., Gwinn, M., Dougherty, B., Tomb, J.F., Fleischmann, R.D., Richardson, D., Peterson, J., Kerlavage, A.R., Quackenbush, J., Salzberg, S., Hanson, M., van Vugt, R., Palmer, N., Adams, M.D., Gocayne, J. \& Venter, J.C. (1997) Genomic sequence of a Lyme disease spirochaete, Borrelia burgdorferi. Nature 390, 580-586.

Furuya, N. \& Komano, T. (1996) Nucleotide sequence and characterization of the trbABC region of the IncI1 Plasmid R64: existence of the pnd gene for plasmid maintenance within the transfer region. J. Bacteriol. 178, 1491-1497.

Gazit, E. \& Sauer, R.T. (1999a) The Doc toxin and Phd antidote proteins of the bacteriophage P1 plasmid addiction system form a heterotrimeric complex. J. Biol. Chem. 274, 16813-16818. 
Gazit, E. \& Sauer, R.T. (1999b) Stability and DNA binding of the phd protein of the phage P1 plasmid addiction system. J. Biol. Chem. 274, 2652-2657.

Gerdes, K., Bech, F.W., Jorgensen, S.T., Lobner-Olesen, A., Rasmussen, P.B., Atlung, T., Boe, L., Karlstrom, O., Molin, S. \& von Meyenburg, K. (1986) Mechanism of postsegregational killing by the hok gene product of the parB system of plasmid R1 and its homology with the relF gene product of the $E$. coli relB operon. EMBO J. 5, 2023-2029.

Gerdes, K., Helin, K., Christensen, O.W. \& Lobner-Olesen, A. (1988) Translational control and differential RNA decay are key elements regulating postsegregational expression of the killer protein encoded by the parB locus of plasmid R1. J. Mol. Biol. 203, $119-129$.

Gerdes, K., Poulsen, L.K., Thisted, T., Nielsen, A.K., Martinussen, J. \& Andreasen, P.H. (1990) The hok killer gene family in gram-negative bacteria. New Biol. 2, 946-956.

Gerdes, K., Nielsen, A., Thorsted, P. \& Wagner, E.G. (1992) Mechanism of killer gene activation. Antisense RNA-dependent RNase III cleavage ensures rapid turn-over of the stable hok, srnB and pndA effector messenger RNAs. J. Mol. Biol. 226, 637-649.

Gerdes, K., Gultyaev, A.P., Franch, T., Pedersen, K. \& Mikkelsen, N.D. (1997) Antisense RNA-regulated programmed cell death. Annu. Rev. Genet. 31, 1-31.

Gerdes, K., Moller-Jensen, J. \& Bugge, J.R. (2000) Plasmid and chromosome partitioning: Surprises from phylogeny. Mol. Microbiol. 37, 455-466.

Gerdes, K. (2000) Toxin-antitoxin modules may regulate synthesis of macromolecules during nutritional stress. J. Bacteriol. 182, 561-572.

Gerdes, K., Aroya, S., Canosa, I., Ceglowski, P., Diaz-Orejas, R., Franch, T., Gultyaev, A.P., Bugge Jensen, R., Kobayashi, I., Macpherson, C., Summers, D., Thomas, C.M. \& Zielenkiewicz, U. (2000) A novel proteic plasmid stabilization system from Gram-positive bacteria. in The Horizontal Gene Pool. Bacterial
Plasmids and Gene Spread. (Thomas, C.M., ed) pp. 66-67, Harwood Academic Publishers.

Golub, E.I. \& Panzer, H.A. (1988) The F factor of Escherichia coli carries a locus of stable plasmid inheritance stm, similar to the parB locus of plasmid RI. Mol. Gen. Genet. 214, $353-357$.

Gordon, G.S., Sitnikov, D., Webb, C.D., Teleman, A., Straight, A., Losick, R., Murray, A.W. \& Wright, A. (1997) Chromosome and low copy plasmid segregation in E. coli: Visual evidence for distinct mechanisms. Cell 90, 1113-1121.

Gotfredsen, M. \& Gerdes, K. (1998) The Escherichia coli relBE genes belong to a new toxin-antitoxin gene family. Mol. Microbiol. 29, 1065-1076.

Greenfield, T.J., Ehli, E., Kirshenmann, T., Franch, T., Gerdes, K. \& Weaver, K.E. (2000) The antisense RNA of the par locus of pAD1 regulates the expression of a 33-amino-acid toxic peptide by an unusual mechanism. Mol. Microbiol. 37, 652-660.

Grinter, N.J., Brewster, G. \& Barth, P.T. (1989) Two mechanisms necessary for the stable inheritance of plasmid RP4. Plasmid 22, 203-214.

Grønlund, H. \& Gerdes, K. (1999) Toxin-antitoxin systems homologous with relBE of Escherichia coli plasmid P307 are ubiquitous in prokaryotes. J. Mol. Biol. 285, 1401-1415.

Hayes, F. (1998) A family of stability determinants in pathogenic bacteria. J. Bacteriol. 180, 6415-6418.

Hayes, F. (2000) The partition system of multidrug resistance plasmid TP228 includes a novel protein that epitomizes an evolutionarily distinct subgroup of the ParA superfamily. Mol. Microbiol. 37, 528-541.

Hazan, R., Sat, B., Reches, M. \& Engelberg-Kulka, H. (2001) Postsegregational killing mediated by the P1 phage "Addiction Module“ phd-doc requires the Escherichia coli programmed cell death system mazEF. J. Bacteriol. 183, 2046-2050.

Hiraga, S. (1992) Chromosome and plasmid partition in Escherichia coli. Annu. Rev. Biochem. 61, 283-306. 
Honeycutt, R.J., McClelland, M. \& Sobral, B.W. (1993) Physical map of the genome of Rhizobium meliloti 1021. J. Bacteriol. 175, 69456952.

Jack, R.W., Tagg, J.R. \& Ray, B. (1995) Bacteriocins of gram-positive bacteria. Microbiol. Rev. 59, 171-200.

Jack, R.W. \& Jung, G. (2000) Lantibiotics and microcins: Polypeptides with unusual chemical diversity. Curr. Opin. Chem. Biol. 4, 310317.

Jaffe, A., Ogura, T. \& Hiraga, S. (1985) Effects of the ccd function of the $\mathrm{F}$ plasmid on bacterial growth. J. Bacteriol. 163, 841-849.

Janniere, L., McGovern, S., Pujol, C., Petit, M.A. \& Ehrlich, S.D. (1996) In vivo analysis of the plasmid pAM beta 1 resolution system. Nucleic Acids Res. 24, 3431-3436.

Jensen, R.B. \& Gerdes, K. (1995) Programmed cell death in bacteria: proteic plasmid stabilization systems. Mol. Microbiol. 17, 205-210.

Jensen, R.B., Grohmann, E., Schwab, H., Diaz-Orejas, R. \& Gerdes, K. (1995) Comparison of ccd of F, parDE of RP4, and parD of R1 using a novel conditional replication control system of plasmid R1. Mol. Microbiol. 17, 211-220.

Jensen, R.B. \& Gerdes, K. (1999) Mechanism of DNA segregation in prokaryotes: ParM partitioning protein of plasmid R1 co-localizes with its replicon during the cell cycle. EMBO J. 18, 4076-4084.

Johnson, E.P., Strom, A.R. \& Helinski, D.R. (1996) Plasmid RK2 toxin protein ParE: Purification and interaction with the ParD antitoxin protein. J. Bacteriol. 178, 1420-1429.

Jovanovic, O.S., Ayres, E.K. \& Figurski, D.H. (1994) Host-inhibitory functions encoded by promiscuous plasmids. Transient arrest of Escherichia coli segregants that fail to inherit plasmid RK2. J. Mol. Biol. 237, 52-64.

Karoui, H., Bex, F., Dreze, P. \& Couturier, M. (1983) Ham22, a mini-F mutation which is lethal to host cell and promotes recA-dependent induction of lambdoid prophage. EMBO J. $\mathbf{2}$, 1863-1868.
Kim, S.K. \& Wang, J.C. (1998) Localization of F plasmid SopB protein to positions near the poles of Escherichia coli cells. Proc. Natl. Acad. Sci. U.S.A 95, 1523-1527.

Kobayashi, I. (1998) Selfishness and death: Raison d'etre of restriction, recombination and mitochondria. Trends Genet. 14, 368-374.

Koyama, A.H., Wada, C., Nagata, T. \& Yura, T. (1975) Indirect selection for plasmid mutants: Isolation of ColVBtrp mutants defective in self-maintenance in Escherichia coli. J. Bacteriol. 122, 73-79.

Kusano, K., Naito, T., Handa, N. \& Kobayashi, I. (1995) Restriction-modification systems as genomic parasites in competition for specific sequences. Proc. Natl. Acad. Sci. U.S.A 92, 11095-11099.

Kusukawa, N., Mori, H., Kondo, A. \& Hiraga, S. (1987) Partitioning of the F plasmid: Overproduction of an essential protein for partition inhibits plasmid maintenance. Mol. Gen. Genet. 208, 365-372.

Lane, D., de Feyter, R., Kennedy, M., Phua, S.H. \& Semon, D. (1986) D protein of miniF plasmid acts as a repressor of transcription and as a site-specific resolvase. Nucleic Acids Res. 14, 9713-9728.

Lavalle, R. (1965) New mutants for regulation of RNA synthesis. Bull. Soc. Chim. Biol. (Paris) 47, 1567-1570.

Lehnherr, H., Maguin, E., Jafri, S. \& Yarmolinsky, M.B. (1993) Plasmid addiction genes of bacteriophage P1: doc, which causes cell death on curing of prophage, and phd, which prevents host death when prophage is retained. $J$. Mol. Biol. 233, 414-428.

Lehnherr, H. \& Yarmolinsky, M.B. (1995) Addiction protein $\mathrm{Phd}$ of plasmid prophage $\mathrm{P} 1$ is a substrate of the ClpXP serine protease of Escherichia coli. Proc. Natl. Acad. Sci. U.S.A 92, 3274-3277.

Łobocka, M. \& Yarmolinsky, M. (1996) P1 plasmid partition: A mutational analysis of ParB. J. Mol. Biol. 259, 366-382.

Loh, S.M., Cram, D.S. \& Skurray, R. A. (1988) Nucleotide sequence and transcriptional analysis 
of a third function (Flm) involved in F-plasmid maintenance. Gene 66, 259-268.

Loris, R., Dao-Thi, M.H., Bahassi, E.M., Van Melderen, L., Poortmans, F., Liddington, R., Couturier, M. \& Wyns, L. (1999) Crystal structure of $\mathrm{CcdB}$, a topoisomerase poison from $E$. coli. J. Mol. Biol. 285, 1667-1677.

Lynch, A.S. \& Wang, J.C. (1995) SopB protein-mediated silencing of genes linked to the sopC locus of Escherichia coli F plasmid. Proc. Natl. Acad. Sci. U.S.A 92, 1896-1900.

Magnuson, R. \& Yarmolinsky, M.B. (1998) Corepression of the P1 addiction operon by Phd and Doc. J. Bacteriol. 180, 6342-6351.

Maki, S., Takiguchi, S., Horiuchi, T., Sekimizu, K. \& Miki, T. (1996) Partner switching mechanisms in inactivation and rejuvenation of Escherichia coli DNA gyrase by F plasmid proteins LetD (CcdB) and LetA (CcdA). J. Mol. Biol. 256, 473-482.

Miki, T., Chang, Z.T. \& Horiuchi, T. (1984) Control of cell division by sex factor $\mathrm{F}$ in Escherichia coli. II. Identification of genes for inhibitor protein and trigger protein on the 42.84-43.6 F segment. J. Mol. Biol. 174, 627-646.

Miki, T., Park, J.A., Nagao, K., Murayama, N. \& Horiuchi, T. (1992) Control of segregation of chromosomal DNA by sex factor F in Escherichia coli. Mutants of DNA gyrase subunit A suppress letD (ccdB) product growth inhibition. J. Mol. Biol. 225, 39-52.

Mohl, D.A. \& Gober, J.W. (1997) Cell cycle-dependent polar localization of chromosome partitioning proteins in Caulobacter crescentus. Cell 88, 675-684.

Mori, H., Mori, Y., Ichinose, C., Niki, H., Ogura, T., Kato, A. \& Hiraga, S. (1989) Purification and characterization of SopA and SopB proteins essential for $\mathrm{F}$ plasmid partitioning. J. Biol. Chem. 264, 15535-15541.

Motallebi-Veshareh, M., Rouch, D.A. \& Thomas, C.M. (1990) A family of ATPases involved in active partitioning of diverse bacterial plasmids. Mol. Microbiol. 4, 1455-1463.

Motallebi-Veshareh, M., Balzer, D., Lanka, E., Jagura-Burdzy, G. \& Thomas, C.M. (1992) Conjugative transfer functions of broad-host- range plasmid RK2 are coregulated with vegetative replication. Mol. Microbiol. 6, 907-920.

Naito, T., Kusano, K. \& Kobayashi, I. (1995) Selfish behavior of restriction-modification systems. Science 267, 897-899.

Nielsen, A.K., Thorsted, P., Thisted, T., Wagner, E.G. \& Gerdes, K. (1991) The rifampicin-inducible genes srnB from $\mathrm{F}$ and pnd from $\mathrm{R} 483$ are regulated by antisense RNAs and mediate plasmid maintenance by killing of plasmid-free segregants. Mol. Microbiol. 5, 1961-1973.

Nordstrom, K. \& Austin, S.J. (1989) Mechanisms that contribute to the stable segregation of plasmids. Annu. Rev. Genet. 23, 37-69.

Ogura, T. \& Hiraga, S. (1983) Mini-F plasmid genes that couple host cell division to plasmid proliferation. Proc. Natl. Acad. Sci. U.S.A 80, 4784-4788.

Ohnishi, Y., Iguma, H., Ono, T., Nagaishi, H. \& Clark, A.J. (1977) Genetic mapping of the F plasmid gene that promotes degradation of stable ribonucleic acid in Escherichia coli. J. Bacteriol. 132, 784-789.

Ono, K., Akimoto, S. \& Ohnishi, Y. (1987) Nucleotide sequence of the pnd gene in plasmid R483 and role of the pnd gene product in plasmolysis. Microbiol. Immunol. 31, 1071-1083.

Ono, K., Akimoto, S., Ono, T. \& Ohnishi, Y. (1986) Plasmid genes increase membrane permeability in Escherichia coli. Biochim. Biophys. Acta 867, 81-88.

Pansegrau, W., Lanka, E., Barth, P.T., Figurski, D.H., Guiney, D.G., Haas, D., Helinski, D.R., Schwab, H., Stanisich, V.A. \& Thomas, C M. (1994) Complete nucleotide sequence of Birmingham IncP alpha plasmids. Compilation and comparative analysis. J. Mol. Biol. 239, $623-663$.

Pedersen, K. \& Gerdes, K. (1999) Multiple hok genes on the chromosome of Escherichia coli. Mol. Microbiol. 32, 1090-1102.

Poulsen, L.K., Larsen, N.W., Molin, S. \& Andersson, P. (1989) A family of genes encoding a cell-killing function may be conserved in 
all gram-negative bacteria. Mol. Microbiol. 3, 1463-1472.

Roberts, R.C., Burioni, R. \& Helinski, D.R. (1990) Genetic characterization of the stabilizing functions of a region of broad-host-range plasmid RK2. J. Bacteriol. 172, 6204-6216.

Roberts, R.C. \& Helinski, D.R. (1992) Definition of a minimal plasmid stabilization system from the broad- host-range plasmid RK2. J. Bacteriol. 174, 8119-8132.

Roberts, R.C., Spangler, C. \& Helinski, D.R. (1993) Characteristics and significance of DNA binding activity of plasmid stabilization protein ParD from the broad-host-range plasmid RK2. J. Biol. Chem. 268, 27109-27117.

Roberts, R.C., Strom, A.R. \& Helinski, D.R. (1994) The parDE operon of the broad-host-range plasmid RK2 specifies growth inhibition associated with plasmid loss. J. Mol. Biol. 237, 35-51.

Rodionov, O., Lobocka, M. \& Yarmolinsky, M. (1999) Silencing of genes flanking the P1 plasmid centromere. Science 283, 546-549.

Rojo, F. \& Alonso, J.C. (1994) A novel site-specific recombinase encoded by the Streptococcus pyogenes plasmid pSM19035. J. Mol. Biol. 238, 159-172.

Ruiz-Echevarria, M.J., Berzal-Herranz, A., Gerdes, K. \& Diaz-Orejas, R. (1991a) The kis and kid genes of the parD maintenance system of plasmid R1 form an operon that is autoregulated at the level of transcription by the co- ordinated action of the Kis and Kid proteins. Mol. Microbiol. 5, 2685-2693.

Ruiz-Echevarria, M.J., de Torrontegui, G., Gimenez-Gallego, G. \& Diaz-Orejas, R. (1991b) Structural and functional comparison between the stability systems ParD of plasmid R1 and Ced of plasmid F. Mol. Gen. Genet. 225, 355-362.

Ruiz-Echevarria, M.J., Gimenez-Gallego, G., Sabariegos-Jareno, R. \& Diaz-Orejas, R. (1995) $\mathrm{Kid}$, a small protein of the parD stability system of plasmid R1, is an inhibitor of DNA replication acting at the initiation of DNA synthesis. J. Mol. Biol. 247, 568-577.
Sakikawa, T., Akimoto, S. \& Ohnishi, Y. (1989) The pnd gene in E. coli plasmid R16: Nucleotide sequence and gene expression leading to cell $\mathrm{Mg}^{2+}$ release and stable RNA degradation. Biochim. Biophys. Acta 1007, 158-166.

Salmon, M.A., Van Melderen, L., Bernard, P. \& Couturier, M. (1994) The antidote and autoregulatory functions of the $\mathrm{F}$ plasmid CcdA protein: A genetic and biochemical survey. Mol. Gen. Genet. 244, 530-538.

Santos-Sierra, S., Giraldo, R. \& Diaz-Orejas, R. (1997) Functional interactions between homologous conditional killer systems of plasmid and chromosomal origin. FEMS Microbiol. Lett. 152, 51-56.

Sat, B., Hazan, R., Fisher, T., Khaner, H., Glaser, G. \& Engelberg-Kulka, H. (2001) Programmed cell death in Escherichia coli: Some antibiotics can trigger mazEF lethality. J. Bacteriol. 183, 2041-2045.

Sharpe, M.E. \& Errington, J. (1996) The Bacillus subtilis soj-spo0J locus is required for a centromere-like function involved in prespore chromosome partitioning. Mol. Microbiol. 21, 501-509.

Sharpe, M.E., Chatwin, H.M., Macpherson, C., Withers, H.L. \& Summers, D.K. (1999) Analysis of the CoIE1 stability determinant Rcd. $M i$ crobiology 145, 2135-2144.

Sia, E.A., Roberts, R.C., Easter, C., Helinski, D.R. \& Figurski, D.H. (1995) Different relative importances of the par operons and the effect of conjugal transfer on the maintenance of intact promiscuous plasmid RK2. J. Bacteriol. 177, 2789-2797.

Smith, A.S. \& Rawlings, D.E. (1997) The poison-antidote stability system of the broadhost-range Thiobacillus ferrooxidans plasmid pTF-FC2. Mol. Microbiol. 26, 961-970.

Smith, A.S. \& Rawlings, D.E. (1998a) Autoregulation of the pTF-FC2 proteic poison-antidote plasmid addiction system (pas) is essential for plasmid stabilization. J. Bacteriol. 180, 5463-5465.

Smith, A.S. \& Rawlings, D.E. (1998b) Efficiency of the pTF-FC2 pas poison-antidote stability system in Escherichia coli is affected by the host 
strain, and antidote degradation requires the lon protease. J. Bacteriol. 180, 5458-5462.

Steiner, W.W. \& Kuempel, P.L. (1998) Cell division is required for resolution of dimer chromosomes at the dif locus of Escherichia coli. Mol. Microbiol. 27, 257-268.

Summers, D. (1998) Timing, self-control and a sense of direction are the secrets of multicopy plasmid stability. Mol. Microbiol. 29, 1137-1145.

Summers, D.K. \& Sherratt, D.J. (1984) Multimerization of high copy number plasmids causes instability: CoIE1 encodes a determinant essential for plasmid monomerization and stability. Cell 36, 1097-1103.

Tam, J.E. \& Kline, B.C. (1989) The F plasmid ccd autorepressor is a complex of $\mathrm{CcdA}$ and $\mathrm{CcdB}$ proteins. Mol. Gen. Genet. 219, 26-32.

Thisted, T., Sorensen, N.S., Wagner, E.G. \& Gerdes, K. (1994) Mechanism of post-segregational killing: Sok antisense RNA interacts with Hok mRNA via its 5'-end single-stranded leader and competes with the 3 '-end of Hok mRNA for binding to the mok translational initiation region. EMBO J. 13, 1960-1968.

Thisted, T., Nielsen, A.K. \& Gerdes, K. (1994) Mechanism of post-segregational killing: Translation of Hok, SrnB and Pnd mRNAs of plasmids R1, F and R483 is activated by 3'-end processing. EMBO J. 13, 1950-1959.

Tian, Q.B., Hayashi, T., Murata, T. \& Terawaki, Y. (1996b) Gene product identification and promoter analysis of hig locus of plasmid Rts1. Biochem. Biophys. Res. Commun. 225, 679-684.

Tian, Q.B., Ohnishi, M., Tabuchi, A. \& Terawaki, Y. (1996a) A new plasmid-encoded proteic killer gene system: Cloning, sequencing, and analyzing hig locus of plasmid Rts1. Biochem. Biophys. Res. Commun. 220, 280-284.

Tsuchimoto, S., Ohtsubo, H. \& Ohtsubo, E. (1988) Two genes, pemK and pemI, responsible for stable maintenance of resistance plasmid R100. J. Bacteriol. 170, 1461-1466.

Tsuchimoto, S. \& Ohtsubo, E. (1989) Effect of the pem system on stable maintenance of plasmid
R100 in various Escherichia coli hosts. Mol. Gen. Genet. 215, 463-468.

Tsuchimoto, S., Nishimura, Y. \& Ohtsubo, E. (1992) The stable maintenance system pem of plasmid R100: Degradation of PemI protein may allow PemK protein to inhibit cell growth. J. Bacteriol. 174, 4205-4211.

Van Melderen, L., Bernard, P. \& Couturier, M. (1994) Lon-dependent proteolysis of CcdA is the key control for activation of $\mathrm{CcdB}$ in plasmid-free segregant bacteria. Mol. Microbiol. 11, 1151-1157.

Watanabe, E., Inamoto, S., Lee, M.H., Kim, S.U., Ogua, T., Mori, H., Hiraga, S., Yamasaki, M. \& Nagai, K. (1989) Purification and characterization of the sopB gene product which is responsible for stable maintenance of mini-F plasmid. Mol. Gen. Genet. 218, 431-436.

Weaver, K.E. \& Clewell, D.B. (1989) Construction of Enterococcus faecalis pAD1 miniplasmids: Identification of a minimal pheromone response regulatory region and evaluation of a novel pheromone-dependent growth inhibition. Plasmid 22, 106-119.

Weaver, K.E., Jensen, K.D., Colwell, A. \& Sriram, S.I. (1996) Functional analysis of the Enterococcus faecalis plasmid pAD1-encoded stability determinant par. Mol. Microbiol. 20, $53-63$.

Wu, K., Jahng, D. \& Wood, T.K. (1994) Temperature and growth rate effects on the hok/sok killer locus for enhanced plasmid stability. Biotechnol. Prog. 10, 621-629.

Yamaichi, Y., Iida, T., Park, K.S., Yamamoto, K. \& Honda, T. (1999) Physical and genetic map of the genome of Vibrio parahaemolyticus: Presence of two chromosomes in Vibrio species. Mol. Microbiol. 31, 1513-1521.

Yarmolinsky, M.B. (1995) Programmed cell death in bacterial populations. Science $\mathbf{2 6 7}$, 836-837.

Zielenkiewicz, U., Sitkiewicz, I., Kern-Zdanowicz, I. \& Cegłowski, P. (2000) Activity of a postsegregational killing system of the plasmid pSM19035 in Bacillus subtilis cells. Plasmid 45, 156. 